\title{
PERPENDICULAR MAGNETIC ANISOTROPY AND MAGNETO- OPTICAL PROPERTIES IN Fe(Co)/Pt MULTILAYER FILMS
}

\author{
S. Iwata*, H. Notarys, S. S. P. Parkin and T. Suzuki \\ IBM Research Division, Almaden Research Center, \\ 650 Harry Road, San Jose, CA 95120-6099, U.S.A. \\ *Dep. Electronics, Nagoya University, Nagoya, Japan
}

\begin{abstract}
A systematic study on structure, magnetic and magneto-optical properties of $\mathrm{Fe} / \mathrm{Pt}$ and $\mathrm{FeCo} / \mathrm{Pt}$ multilayer films has been performed. It is found that the microstructure observed by cross-sectional TEM as well as the effective perpendicular anisotropy $\mathrm{K}_{\text {eff }}$ varied according as substrate-deposition-temperature. In Fe/Pt multilayer film deposited on the substrate above room temperature, a fine columnar structure were discerned and the perpendicular anisotropy was fairly large. In the sample grown on a cooling substrate, however, the structure with irregular small crystal grains appeared instead of a columnar structure and the $\mathrm{K}_{\text {eff }}$ reduced. This result implies that the columnar microstructure contributes to the perpendicular anisotropy of multilayer films.
\end{abstract}

\section{KEYWORDS : MULTILAYER, PERPENDICULAR ANISOTROPY, MAGNETO-OPTICS, COLUMNAR STRUCTURE, CURIE TEMPERATURE}

\section{INTRODUCTION}

Since $\mathrm{Co} / \mathrm{Pt}$ and $\mathrm{Co} / \mathrm{Pd}$ multilayer films exhibit a strong perpendicular magnetic anisotropy and a large magneto-optical Kerr effect at short wavelength $[1,2]$, they are considered to be potential candidates for magneto-optical recording media at a blue-wavelength. On the other hand, although $\mathrm{Fe} / \mathrm{Pt}$ multilayers also exhibit a perpendicular anisotropy and an enhancement of Kerr rotation at short wavelength, the magnitude of the anisotropy is not sufficient for practice use as a magneto-optical recording media [3-5]. The origin of the perpendicular anisotropy in transition metal and novel metal multilayer films is considered to be magnetocrystalline surface anisotropy [6] and magneto-elastic effect at the interfaces [7,8]. However, a very little work has been made on the correlation between the perepndicular anisotropy and the microstructure of the films $[9,10]$.

The present paper describes a detailed results of magnetic and magneto-optical properties of $\mathrm{Fe} / \mathrm{Pt}$ and $\mathrm{FeCo} / \mathrm{Pt}$ multilayer films. In particular, to reveal the origin of the anisotropy, we investigated the substratedeposition-temperature dependence on the anisotropy and the microstructure.

\section{EXPERIMENTAL}

$\mathrm{Fe} / \mathrm{Pt}$ multilayer films were prepared onto glass (Corning \#7059), fused quartz and Si substrates by electron-beam evaporation method. The base pressure before deposition was $1.0 \sim 1.6 \times 10^{-8}$ torr and the pressure during the deposition was better than $5 \times 10^{-8}$ torr. The deposition rate was $0.10 \sim 0.20 \AA / \mathrm{s}$ for the Fe layers and $0.35 \sim 0.40 \AA / \mathrm{s}$ for the Pt layers. The substrate-deposition-temperature $T_{S}$ was varied from $165^{\circ} \mathrm{C}$ to $220^{\circ} \mathrm{C}$. The first layer is $\mathrm{Fe}$ and the surface layer is $\mathrm{Pt}$.

$\left(\mathrm{Fe}_{50} \mathrm{Co}_{50}\right) / \mathrm{Pt}$ multilayer films were prepared by $\mathrm{dc}$ sputtering deposition onto $50 \AA \mathrm{Pt}$ buffer layer deposited on Si substrate. The number of the bilayers was 30 and the thickness of the final Pt layer was fixed to $30 \AA$.

The crystallographical structure was examined by $X R D$. The magnetic properties were obtained from VSM and torque magnetometer. The cross-sectional transmission electron microscopy (TEM) were used to examine the microstructure of the films.

\section{RESULTS AND DISCUSSION}

\section{A. Perpendicular Anisotropy for Fe/Pt and $\mathrm{FeCo} / \mathrm{Pt}$ multilayer Films}

Figure 1 shows the $\mathrm{Fe}$ and $\mathrm{FeCo}$ thickness $\mathrm{t}$ dependence of $t \cdot K_{\text {eff }}$, where $K_{\text {eff }}$ is the effective perpendicular anisotropy constant per unit $\mathrm{Fe}$ and FeCo volume, which corresponds to the torque amplitude at $20 \mathrm{kOe}$. For the $\mathrm{Fe} / \mathrm{Pt}$, although perpendicular magnetized films are obtained for the $\mathrm{Fe}$ layer thickness less than $3 \AA$, the magnitude of perpendicular anisotropy is rather small. The $\mathrm{K}_{\text {eff }}$ for $\mathrm{FeCo} / \mathrm{Pt}$ multilayer films is improved compared to $\mathrm{Fe} / \mathrm{Pt}$ [11]. However, it still smaller than that for $\mathrm{Co} / \mathrm{Pt}$ multilayers [2]. 


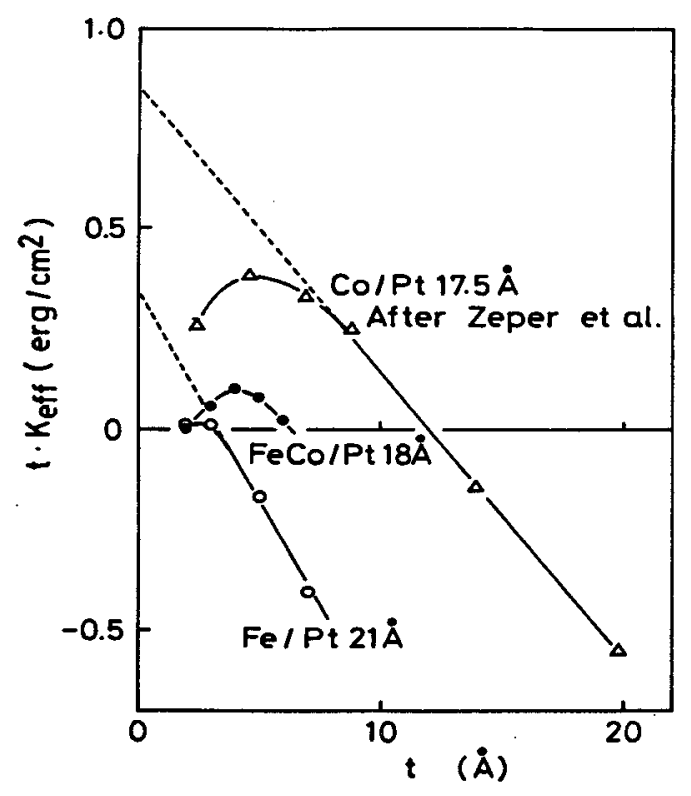

Fig. 1. Magnetic layer thickness $t$ dependence of Effective perepndicular anisotropy $\mathrm{K}_{\mathrm{eff}}$ times $\mathrm{t}$ for $\mathrm{Fe} / \mathrm{Pt}, \mathrm{FeCo} / \mathrm{Pt}$ and $\mathrm{Co} / \mathrm{Pt}[2]$ multilayer films.

\section{B. Microstructure and Perpendicular Anisotropy}

Figures 2 (a) and (b) show the low and wide angle $\mathrm{XRD}$ patterns for $2.5 \AA \mathrm{Fe} / 18 \AA \mathrm{Pt} \times 40$ films, respectively, where the substrate-deposition-temperature $T_{s}$ was varied as a parameter. Figures 3 (a) (c) show the crosssectional TEM images for the films shown in Fig.2. In the photograph of the film grown at $18^{\circ} \mathrm{C}$, the columnar structure with $80 \sim 150 \AA$ width can be seen and the multilayered structure can be also observed within the columns. The similar structure in sputtered $\mathrm{Co} / \mathrm{Pd}$ multilayer films has been reported by Hashimoto et al. [9].

The sample grown at $220^{\circ} \mathrm{C}$ exhibits more densely columnar structure as shown in Fig.3(a). The dense structure and processed crystallization obtained from the heating of substrate result in higher XRD peak of fcc (111) texture compared to the film grown at $18^{\circ} \mathrm{C}$. On the other hand, the multilayer structure can be discerned no longer in the TEM image in Fig.3(a), which is considered to be caused by interdiffusion at the surface between $\mathrm{Fe}$ and Pt layers. The occurrence of interdiffusion in the films prepared on heated substrates would be supported by the fact that the Curie temperature of the $\mathrm{Fe} / \mathrm{Pt}$ multilayers decreases as increasing $\mathrm{T}_{\mathrm{s}}$ as shown in Fig.4 (a). However, the low angle XRD peak arising from artificial periodic structure can be clearly seen in Fig.2 (a), which implies that the compositionally modulated structure is still preserved in spite of the interdiffusion in the high $\mathrm{T}_{\mathrm{s}}$ samples.

In the film prepared onto cooling substrate shown in Fig 3(c), small irregular crystal grains with $80 \AA \sim 120 \AA$ can be observed instead of the columnar structure and the intensity of fcc (111) peak becomes smaller as shown in Fig.2(b). It is also confirmed through XRD rocking curve shown in Fig. 5 that the dispersion of (111) orientation increases as decreasing $T_{s}$.

The effective perpendicular anisotropy $\mathrm{K}_{\text {eff }}$ measured at $77 \mathrm{~K}$ and $293 \mathrm{~K}$ strongly depends on $T_{s}$ as shown Fig.4(b). One possible mechanism accounting for this $T_{S}$ dependence of $K_{e f f}$ is due to the magnetoelastic contribution through stress between the substrate and the film as reported in [5]. However, the influence of the microstructure of the films on the anisotropy should not be ignored. The disappearance of the columnar structure and the increment in dispersion of the (111) orientation in the low $T_{S}$ sample would be one cause of the decrement of $K_{\text {eff }}$. In the high $\mathrm{T}_{\mathrm{s}}$ range, the variation in $\mathrm{K}_{\text {eff }}$ is very small in spite of the following consideration. If the major part of the origin of the perpendicular anisotropy is magnetocrystalline surface anisotropy or magnetoelastic effect at the interfaces, the occurrence of the interdiffusion would affect the anisotropy. For this problem, further investigation should be required.

\section{Magneto-Optical Kerr Effect}

Figure 6 shows the wavelength dependence of Kerr rotation angle $\theta_{\mathbf{k}}$ for $\mathrm{Fe} / \mathrm{Pt}$ and $\mathrm{FeCo} / \mathrm{Pt}$ multilayer films. The $\theta_{\mathrm{k}}$ of $\mathrm{FeCo} / \mathrm{Pt}$ takes a maximum around $290 \mathrm{~nm}$, which is similar to those of $\mathrm{Fe} / \mathrm{Pt}$ and $\mathrm{Co} / \mathrm{Pt}$ [12] multilayers. Comparing the $\theta_{\mathrm{k}}$ spectra for the films of $3 \AA \mathrm{FeCo} / 10 \AA \mathrm{Pt}, 3 \AA \mathrm{Fe} / 9 \AA \mathrm{Pt}$ and $3.4 \AA \mathrm{Co} / 10.2 \AA \mathrm{Pt}$ 
Proceedings of Magneto-Optical Recording International Symposium '92, J. Magn. Soc. Jpn., Vol. 17, Supplement No. S1 (1993), pp. 127-130 (1) 1993 by The Magnetics Society of Japan

whose magnetic and $P t$ layer thickness are nearly same, the value of $\theta_{\mathbf{k}}$ for $\mathrm{FeCo} / \mathrm{Pt}$ is larger than that for $\mathrm{Fe} / \mathrm{Pt}$ while it is smaller than that for $\mathrm{Co} / \mathrm{Pt}$ in the whole region $(270 \leq \lambda \leq 800 \mathrm{~nm})$.

\section{SUMMARY}

The correlation between the structure and the perpendicular anisotropy and magneto-optical properties of $\mathrm{Fe} / \mathrm{Pt}$ and $\mathrm{FeCo} / \mathrm{Pt}$ multilayer films were studied. It is found that the microstructure observed by
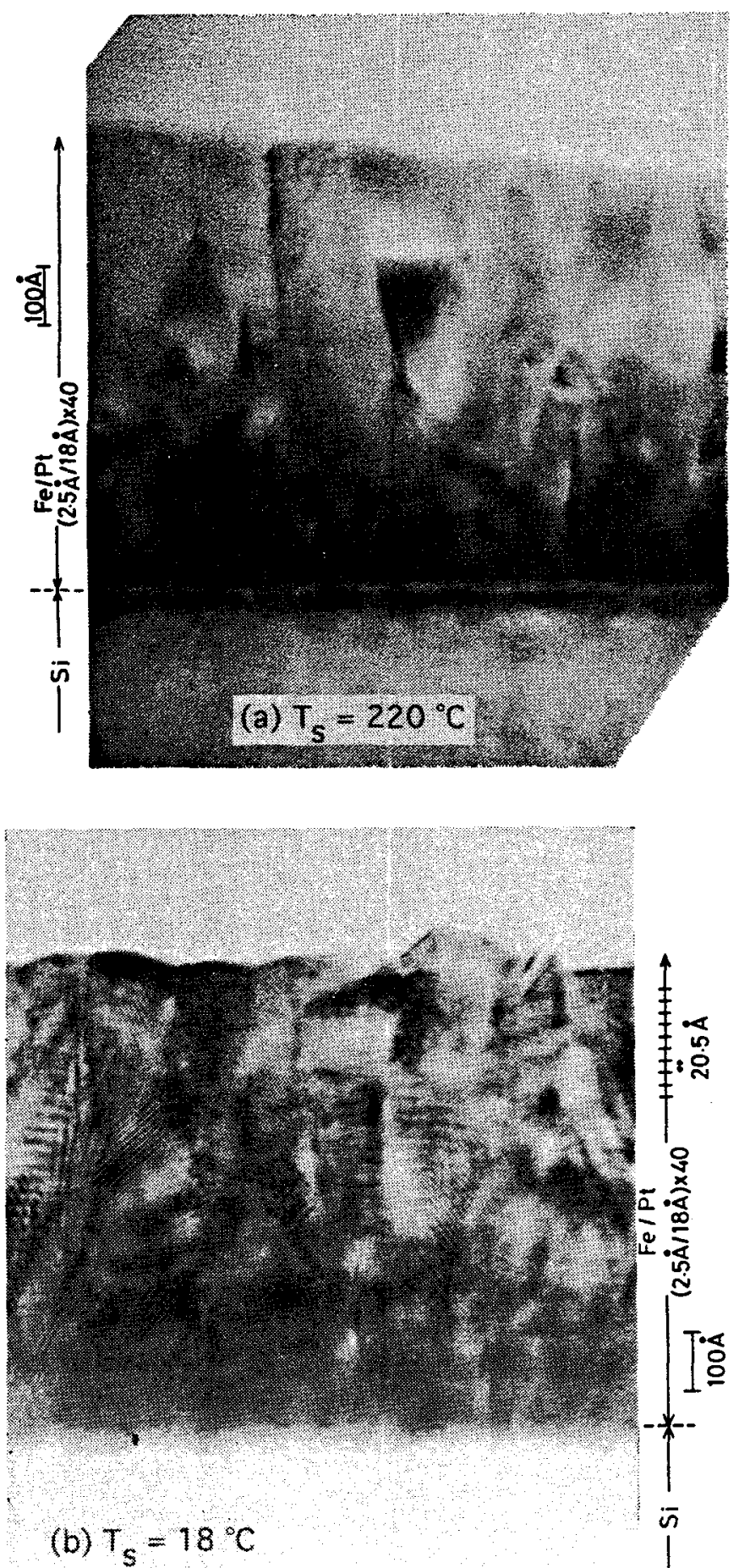

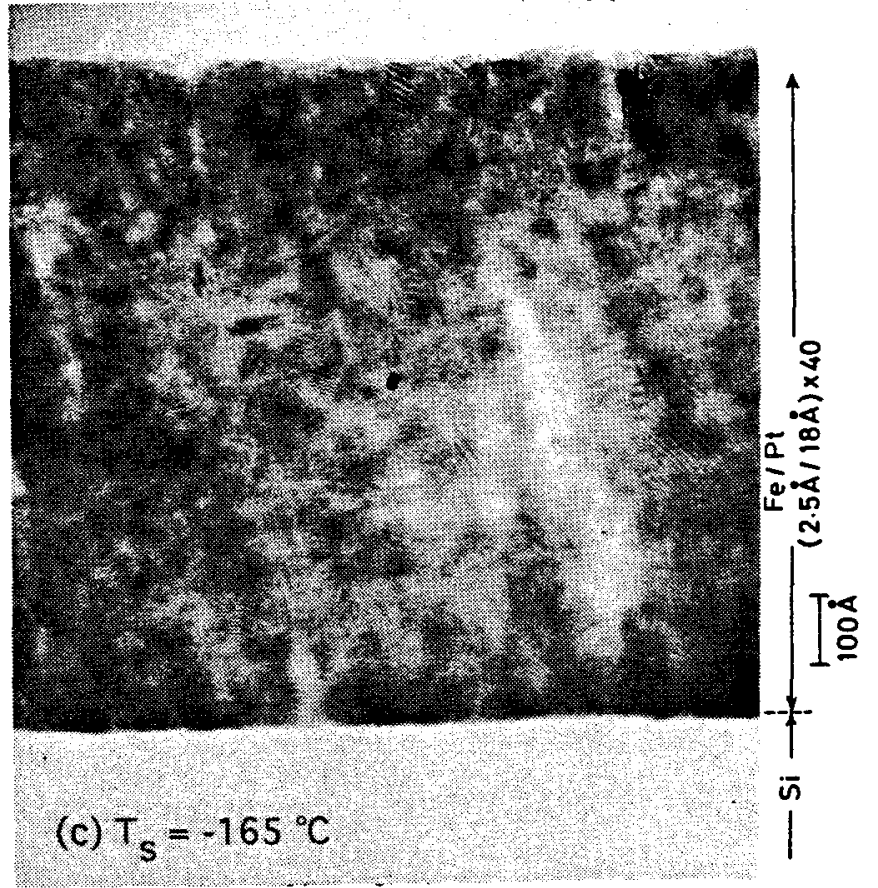

Fig.3. Cross-sectional TEM images for $(2.5 \AA \mathrm{Fe} / 18 \AA \mathrm{Pt}) \times 40$ films with various $T_{s}$

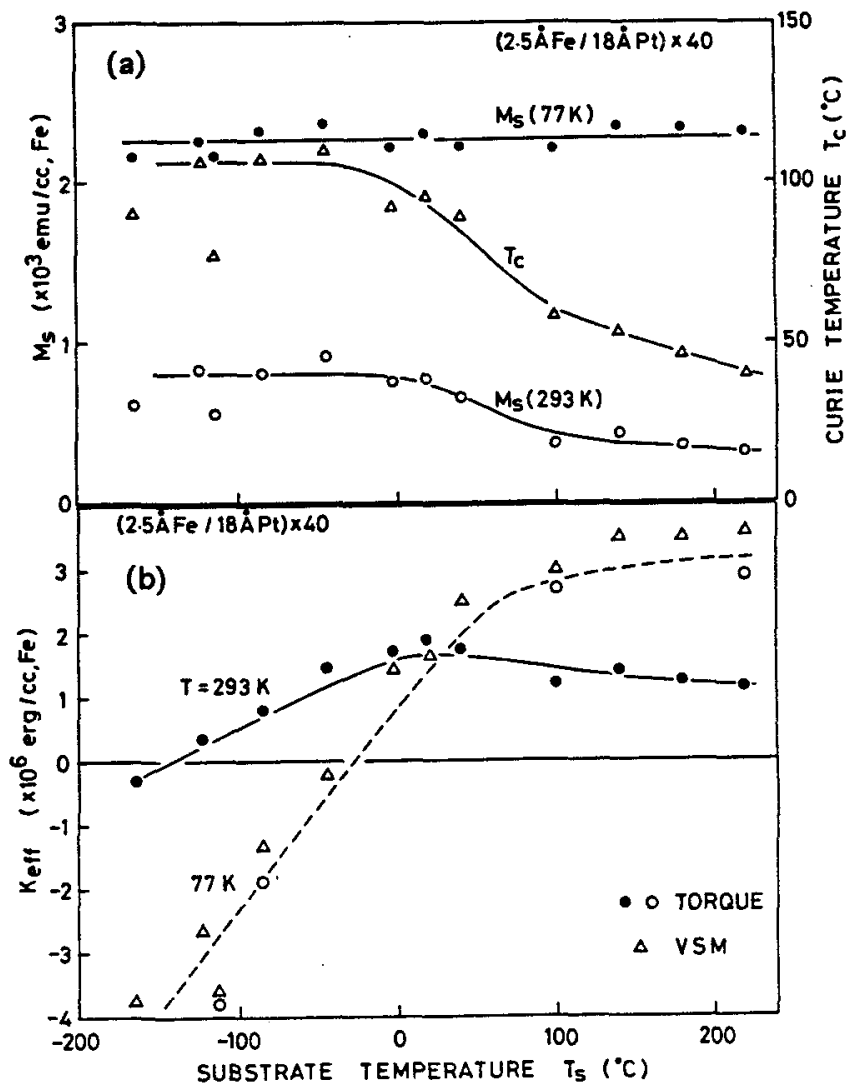

Fig.4. Substrate-deposition-temperature Ts dependence of Curie temperature $T_{c}$, saturation magnetization $M_{s}$ and effective perpendicular anisotropy $\mathrm{K}_{\mathrm{eff}}$ for $(2.5 \AA \mathrm{Fe} / 18 \AA \mathrm{Pt}) \times 40$ films. 


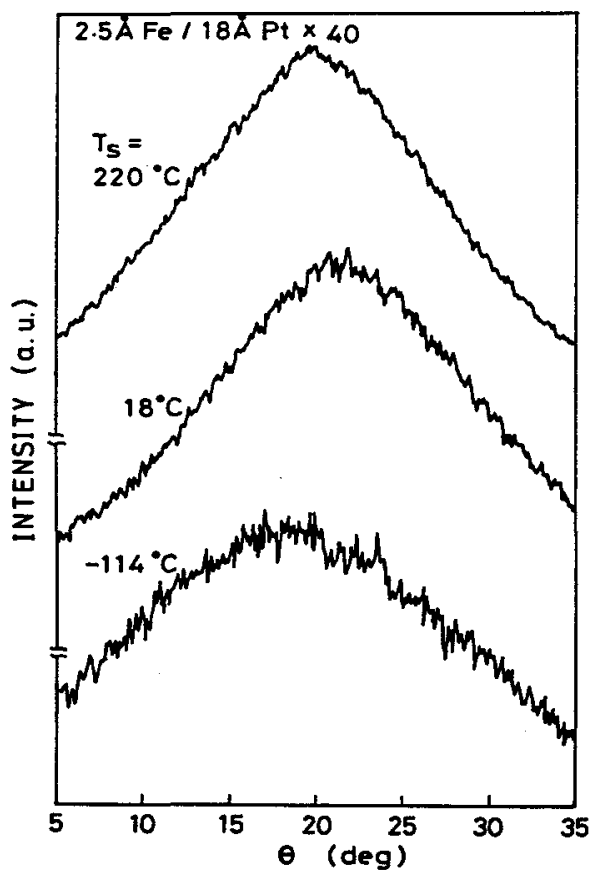

Fig.5. XRD rocking curve of fcc (111) texture for $(2.5 \AA \mathrm{Fe} / 18 \AA \mathrm{Pt}) \times 40$ films.

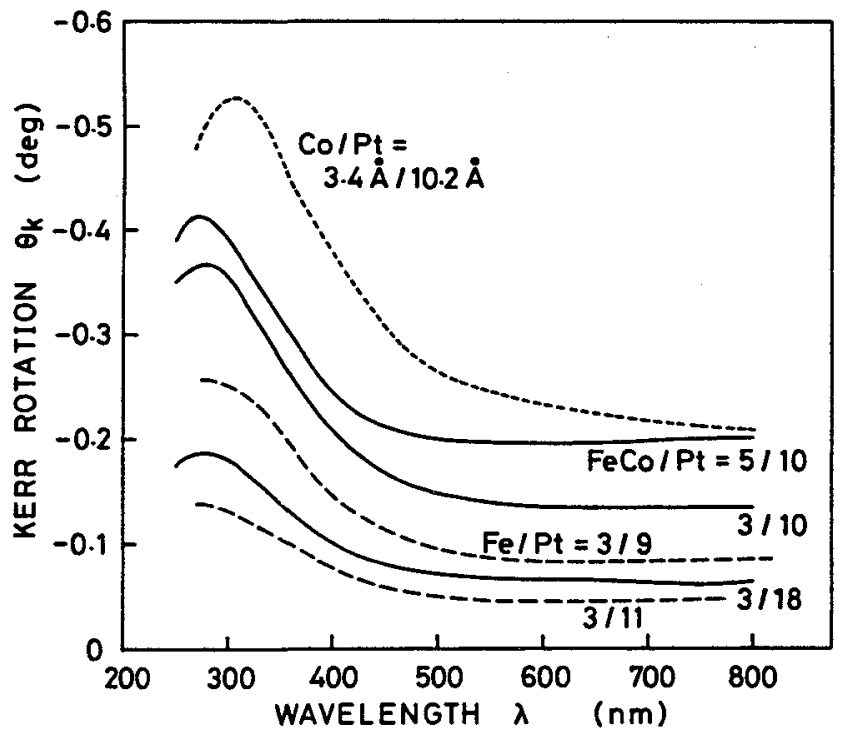

Fig.6. Spectra of Kerr rotation angle $\theta_{\mathrm{k}}$ for $\mathrm{Fe} / \mathrm{Pt}, \mathrm{FeCo} / \mathrm{Pt}$ and $\mathrm{Co} / \mathrm{Pt}[12]$ multilayer films. cross-sectional TEM varied according as substratedeposition-temperature $T_{s}$. The columnar structure with $80 \sim 150 \AA$ width was seen in Fe/Pt multilayer film prepared by electron-beam evaporation at room temperature. If the $\mathrm{T}_{\mathrm{s}}$ was raised to $220^{\circ} \mathrm{C}$, this becomes more densely columnar structure and the interdiffusion occurs. In contrast to this, in the sample grown on cooling substrate, the structure with small irregular crystal grains with $80 \sim 120 \AA$ in diameter appeared instead of columnar structure. The disappearance of columnar structure and the larger dispersion of (111) orientation are considered to be one cause of decrement of effective perpendicular anisotropy in low $\mathrm{T}_{\mathrm{s}}$ samples.

\section{ACKNOWLEDGMENT}

The authors wish to thank Dr. T. Sugimoto of Nihon University for the measurements of the Kerr spectra.

\section{REFERENCES}

[1] P. F. Carcia : J.Appl. Phys., 63, 5066 (1988).

[2] W. B. Zeper, F. J. A. M. Greidanus, P. F. Carcia and C. R. Fincher : J. Appl. Phys., 65, 4971 (1989).

[3] T. Sugimoto, T. Katayama, Y. Suzuki and Y. Nishihara : Jpn. J. Appl. Phys., 28, L2333 (1989).

[4] T. Katayama, Y. Suzuki, Y. Nishihara, T. Sugimoto and M. Hashimoto : J. Appl. Phys., 69, 5658 (1991).

[5] S. Iwata, S. S. P. Parkin, H. Nuri and T. Suzuki : Mat. Res. Soc. Sym. Proc., Vol 232, pp.85-90 (1991).

[6] P. Bruno and J. Seiden : J. de Phys., C8, 1645 (1988).

[7] K. Nakamura, S. Tsunashima, M. Hasegawa and S. Uchiyama : J. Magn. Magn. Mat., 93, 462 (1991).

[8] B. N. Engel, C. D. England, R. A. Van Leeuwen, M. H. Wiedmann and C. M. Falco : J. Appl. Phys., 70, 5873 (1991).

[9] S. Hashimoto, Y. Ochiai and K. Aso : J. Appl. Phys., 66, 4909 (1989).

[10] C. -J. Lin, G. L. Gorman, G. H. Lee, R. F. C. Farrow, E. E. Marinero, H. V. Do, H. Notarys and C. J. Chien : J. Magn. Magn. Mat., 93, 194 (1991).

[11] S. Iwata, S. S. P. Parkin, T. Suzuki and D. Weller : IEEE Trans. Magn., MAG-28, 3231 (1992).

[12] K. Nakamura, S. Tsunashima, S. Iwata and S. Uchiyama : IEEE Trans. Magn., MAG-25, 3758 (1989). 